\title{
PENGARUH TERAPI BEKAM KERING TERHADAP TEKANAN DARAH PADA PASIEN HIPERTENSI PRIMER
}

\author{
THE EFFECT OF DRY CUPPING THERAPY ON \\ BLOOD PRESSURE IN PRIMARY HYPERTENSION \\ PATIENTS
}

\author{
Sang Ayu Ketut Candrawati ${ }^{1}$, Ni Komang Sukraandini ${ }^{2}$ \\ 1,2 Departemen Keperawatan, STIKes Wira Medika
}

\begin{abstract}
Background: Hypertension is one of the non-communicable diseases that causes morbidity and mortality in the world where $9.4 \%$ of deaths each year are due to complications of hypertension. Hypertension is characterized by an increase in systolic pressure $>140$ $\mathrm{mmHg}$ and diastole $>90 \mathrm{mmHg}$. Dry cupping is an alternative therapy used in lowering blood pressure in hypertensive patients. The aim of the study: to determine the effect of dry cupping therapy on blood pressure in primary hypertensive patients. This study is a Quasiexperimental with a One-Group Pretest-Posttest Design approach. The number of samples was 15 patients with primary hypertension who were taken by purposive sampling technique. Measurement of data using digital tension onemed brand. Data analysis using Paired T Test. The results showed that the systolic blood pressure obtained a $\mathrm{p}$ value of 0.000 and the diastolic blood pressure obtained a $p$ value of 0.001 which means that there is an effect of systolic and diastolic blood pressure before and after being given dry cupping therapy. Dry cupping therapy can be used as an alternative therapy for patients with primary hypertension.
\end{abstract}

Keywords: Bloodletting Cupping, Blood Pressure, Primary Hypertension

\begin{abstract}
ABSTRAK
Latar Belakang: hipertensi merupakan salah satu penyakit tidak menular yang menjadi penyebab morbiditas dan mortalitas di dunia. 9,4\% kematian setiap tahunnya diakibatkan karena komplikasi hipertensi. Hipertensi ditandai dengan peningkatan tekanan sistol $>140$ $\mathrm{mmHg}$ dan diastol $>90 \mathrm{mmHg}$. Bekam kering merupakan salah satu terapi alternatif yang digunakan dalam menurunkan tekanan darah pada pasien hipertensi. Tujuaan penelitian: mengetahui adanya pengaruh terapi bekam kering terhadap tekanan darah pada pasien hipertensi primer. Studi ini adalah Quasi-eksperimental dengan pendekatan One-Group Pretest-Posttest Design. Jumlah sampel 15 pasien hipertensi primer yang diambil dengan tehnik purposive sampling. Pengukuran data menggunakan tensi digital merk onemed. Analisis data menggunakan Paired T Test. Hasil penelitian menunjukkan pada tekanan
\end{abstract}


Bali Medika Jurnal.

Vol 8 No 1, 2021: 90-98

ISSN : 2615-7047

DOI: https://doi.org/10.36376/bmj.v8i1

darah sistolik diperoleh nilai $p$ value sebesar 0,000 dan tekanan darah diastolik diperoleh nilai $p$ value sebesar 0,001 ini berarti terdapat pengaruh tekanan darah sistolik dan diastolik sebelum dan sesudah diberikan terapi bekam kering. Terapi bekam kering bisa dijadikan terapi alternatif untuk pasien dengan hipertensi primer.

Kata Kunci : Bekam Kering, Tekanan Darah, Hipertensi Primer

\begin{tabular}{ll}
\hline Alamat Korespondensi & : STIKes Wira Medika Bali \\
Email & : candrawikastar@gmail.com
\end{tabular}

\section{PENDAHULUAN}

Hipertensi merupakan salah satu penyakit tidak menular (PTM) yang menjadi masalah global dan penyumbang angka kesakitan dan kematian di dunia termasuk Indonesia. Hipertensi merupakan factor resiko terhadap kerusakan organ penting seperti otak, jantung, ginjal, retina, pembuluh darah besar (aorta) dan pembuluh darah perifer (PERHI, 2019). Hipertensi atau tekanan darah tinggi adalah gangguan pada sistem pembuluh darah yang mengakibatkan kenaikan tekanan darah diatas normal yaitu tekanan sistol $>140 \mathrm{mmHg}$ dan diastol $>90$ mmHg (Dinas Kesehatan Kabupaten Gianyar, 2017).

Prevalensi kasus hipertensi di dunia berdasarkan data Word Health Organization (WHO) pada tahun 2013 mencapai 26,4\% dan diperkirakan pada tahun 2025 jumlahnya akan meningkat menjadi 29,2\% (Risniati et al., 2019). Dari 972 juta pengidap hipertensi, 333 juta berada di negara maju dan 639 sisanya berada di negara berkembang, termasuk Indonesia (Zaenurrohmah \& Rachmayanti, 2017). Prevalensi hipertensi di Indonesia berdasarkan hasil pengukuran pada penduduk umur $\geq 18$ tahun cenderung meningkat, dimana tahun 2013 prevalensi hipertensi yaitu $25,8 \%$ meningkat menjadi $34,11 \%$ atau dengan 658,201 kasus pada tahun 2018 (Badan Penelitian dan Pengembangan Kesehatan RI, 2018). Data profil Kesehatan Provinsi Bali tahun 2015, hasil pengukuran tekanan darah pada penduduk usia $\geq 18$ tahun, Kabupaten Gianyar menduduki peringkat ke empat dengan jumlah hipertensi yaitu 355.335 kasus (Dinas Kesehatan Provinsi Bali, 2017). Tahun 2016 jumlah penyakit hipertensi di Kabupaten Gianyar berada di urutan ke dua dari 10 besar penyakit tidak menular dengan 18.022 kasus baru dan lama dari segala umur sedangkan di UTP Kesmas Gianyar mencapai 6.856 kasus hipertensi (Dinas Kesehatan Kabupaten Gianyar, 2017).

Sebanyak 9,4\% kematian di seluruh dunia, disebabkan karena komplikasi hipertensi, 45\% kematian karena penyakit jantung dan 51\% kematian karena penyakit stroke (Kemenkes RI, 2014). Penatalaksanaan hipertensi secara umum yaitu melalui terapi farmakologis dan nonfarmakologis. Penatalaksanaan non farmakologi melalui modifikasi gaya hidup seperti penurunan berat badan, retriksi garam, aktivitas fisik, adopsi pola makan DASH, dan terapi komplementer seperti bekam kering (Ahmae, 2019; Muhadi, 2016). 
Bekam kering adalah tindakan non invasif, menggunakan cupping pada titik-titik meridian dan berfungsi memperbaiki mikrosirkulasi pembuluh darah (Ahmae, 2019). Hasil penelitian oleh (Jansen et al., 2012) menyebutkan bahwa terapi bekam kering berpengaruh terhadap penurunan tekanan darah baik sistolik maupun diastolik.

Tujuan penelitian ini adalah untuk mengetahui adanya pengaruh terapi bekam kering terhadap tekanan darah pada pasien hipertensi primer sehingga kita dapat mengetahui apakah terapi bekam kering dapat bermanfaat dalam penanganan pasien hipertensi primer.

\section{METODE PENELITIAN}

Penelitian dilakukan di wilayah kerja UPT Kesmas Blahbatuh II Gianyar. Design penelitian Quasi-eksperimental dengan pendekatan One-Group PretestPosttest. Populasi penelitian adalah pasien hipertensi primer. Penentuan sampel menggunakan tehnik purposive sampling, sampel penelitian sebnyak 15 pasien dengan hipertensi primer.

Variabel dalam penelitian ini adalah tekanan darah systole dan diastole pasien hipertensi primer sebelum dan sesudah diberikan intervensi terapi bekam kering. Pengumpulan data diawali dengan pengukuran tekanan darah pre test yang dilakukan sebelum intervensi. Pemberian terapi bekam kering kombinasi dengan durasi pemberian yaitu satu kali dalam seminggu selama 4 minggu. Pengukuran tekanan darah post test yang dilakukan setelah intervensi.

Analisa data univariat dilakukan untuk mengetahui mean, median, simpang baku (SD), nilai minimal dan maksimal sebelum dan sesudah intervensi. Data yang diperoleh adalah data yang berdistribusi normal maka analisa bivariate menggunakan Uji Paired t test untuk mengetahui perbedaan rata-rata tekanan darah sistole dan diastole pre-post pada kelompok.

\section{HASIL DAN PEMBAHASAN}

A. Hasil Penelitian

1. Hasil Analisa Univariat

a. Karakteristik Responden Penelitian

Tabel 1. karakteristik penelitian berdasarkan Umur, jenis Kelamin, Riwayat

$$
\text { Pekerjaan }
$$

dan Riwayat Pendidikan

\begin{tabular}{cllccc}
\hline No & Variabel & \multicolumn{2}{l}{ Karakteristik } & n & $\%$ \\
\hline \multirow{2}{*}{1} & Umur & a. & Pra lansia (45-59) & 4 & 26,67 \\
& & b. Elderly (60-74) & 11 & 73,33 \\
& & b. & Old (75-89) & 0 & 0
\end{tabular}


DOI: https://doi.org/10.36376/bmj.v8i1

\begin{tabular}{llllcc}
\hline 2 & Jenis kelamin & a. & Laki-laki & 3 & 20 \\
& & b. & Perempuan & 12 & 80 \\
\hline 4 & Riwayat & a. & Buruh & 3 & 20 \\
& pekerjaan & b. & Petani & 9 & 60 \\
& & a. & Pedagang & 3 & 20 \\
& & & & \\
\hline 3 & Riwayat & a. & Sekolah dasar & 15 & 100 \\
& Pendidikan & b. & SMP & 0 & 0 \\
& & c. & SMA & 0 & 0 \\
& & d. & Perguruan Tinggi & 0 & 0 \\
\hline
\end{tabular}

Berdasarkan tabel 1, dapat dilihat karakteristik responden berdasarkan usia yaitu 11 responden $(73,3 \%$ berada pada katagori Elderly atau usia lanjut. Berdasarkan jenis kelamin yaitu 12 responden $(80 \%)$ berjenis kelamin perempuan, berdasarkan riwayat pekerjaan yaitu 9 responden $(60 \%)$ bekerja sebagai petai dan berdasarkan riwayat pendidikan yaitu 15 responden (100\%) tamat Sekolah Dasar (SD).

b. Tekanan Darah sebelum dan setelah diberikan perlakuan terapi bekam kering

Hasil analisis data berdasarkan variabel penelitian yaitu tekanan darah sistole dan diastole pada kelompok kontrol:

Tabel 2.

Hasil Analisa Data Tekanan Darah Sebelum Dan Setelah Diberikan Terapi Bekam Kering Di UPT Kesmas Blahbatuh II Gianyar Tahun 2019

\begin{tabular}{lcccl}
\hline Tekanan Darah & Mean & Std.Dev & Minimum & Maximum \\
\hline Sistolik & & & & \\
Sebelum & 171,60 & 22,64 & 141 & 214 \\
Sesudah & 149,20 & 18,31 & 130 & 190 \\
\hline Diastolik & & & & \\
Sebelum & 93,73 & 11,42 & 77 & 116 \\
Sesudah & 83,13 & 5,99 & 75 & 99 \\
\hline
\end{tabular}

Berdasarkan tabel 1, diperoleh data rata-rata tekanan darah sistolik sebelum terapi bekam kering sebesar $171,60 \mathrm{mmHg}$ dengan standard deviasi 22,64 $\mathrm{mmHg}$, sedangan sesudah terapi bekam kering sebesar $1149,20 \mathrm{mmHg}$ dengan standard deviasi $18,31 \mathrm{mmHg}$. Selanjutnya untuk rata-rata tekanan darah diastolik sebelum terapi bekam kering sebesar 93,73 mmHg dengan standard deviasi 11,42 $\mathrm{mmHg}$, sedangan sesudah terapi bekam kering sebesar $83,13 \mathrm{mmHg}$ dengan standard deviasi 5,99 $\mathrm{mmHg}$.

2. Hasil Analisi Bivariat

Analisis hasil uji statistik menggunakan Uji Paired T Test dengan hasil sebagai berikut : 
Tabel 3.

Pengaruh Terapi Bekam Kering Terhadap Tekanan Darah Pada Pasien Hipertensi Primer

\begin{tabular}{|c|c|c|c|}
\hline Tekanan Darah & Mean & $\begin{array}{l}\text { Sandar } \\
\text { Deviasi }\end{array}$ & p Value \\
\hline $\begin{array}{l}\text { Sistolik } \\
\text { Sebelum dan } \\
\text { sesudah inervensi }\end{array}$ & 22,400 & 13,479 & 0,000 \\
\hline $\begin{array}{l}\text { Diastolik } \\
\text { Sebelum dan } \\
\text { sesudah inervensi }\end{array}$ & 10,600 & 9,164 & 0,001 \\
\hline
\end{tabular}

Berdasarkan tabel 2, diperoleh hasil analisis uji Uji Paired t test pada tekanan darah sistolik diperoleh nilai $p$ value sebesar 0,000 yang berarti terdapat perbedaan rata-rata tekanan darah sistolik sebelum dan sesudah diberikan terapi bekam kering. Selanjutnya pada tekanan darah diastolik diperoleh nilai $p$ value sebesar 0,001 yang berarti terdapat perbedaan ratarata tekanan darah diastolik sebelum dan sesudah diberikan terapi bekam kering.

\section{B. Diskusi Hasil Penelitian}

\section{Tekanan Darah Sebelum dan Sesudah Intervensi Terapi Bekam Kering Pada Pasien Hipertensi Primer.}

Berdasarkan tabel 1, diperoleh data rata-rata tekanan darah sistolik sebelum terapi bekam kering sebesar 171,60 $\mathrm{mmHg}$ dengan standard deviasi $22,64 \mathrm{mmHg}$, sedangan sesudah terapi bekam kering sebesar 1149,20 mmHg dengan standard deviasi $18,31 \mathrm{mmHg}$. Selanjutnya untuk rata-rata tekanan darah diastolik sebelum terapi bekam kering sebesar 93,73 $\mathrm{mmHg}$ dengan standard deviasi 11,42 $\mathrm{mmHg}$, sedangan sesudah terapi bekam kering sebesar $83,13 \mathrm{mmHg}$ dengan standard deviasi 5,99 $\mathrm{mmHg}$.

Hipertensi adalah kondisi dimana hasil pengukuran tekanan darah sistolik (TDS) $\geq 140 \mathrm{mmHg}$ dan/atau hasil pengukuran tekanan darah diastolik (TDD) $\geq 90 \mathrm{mmHg}$ pada yang didapat lewat pengukuran dua kali secara berurutan dengan selang waktu lima menit dalam keadaan cukup istirahat/tenang (Kemenkes.RI, 2014; PERHI, 2019).

Hasil penelitian peneliti pada kelompok kontrol tidak terdapat penurunan tekanan darah diastolik pada sampel hipertensi dengan $p$ value 0,149 peneliti berasumsi sudah terjadi penurunan serotonin pada otak. Respon dari penurunan serotonin ini bisa saja menyebabkan ketidaknyamanan pada pasien seperti perasaan tidak nyaman atau tidak rileks dikarenakan sampel baru pertama kali melakukan terpai bekam. Namun demikian peneliti juga berasumsi, jika terapi bekam diberikan pada jumlah yang lebih banyak akan berkecenderungan untuk terjadi perubahan. 
Bekam kering adalah tindakan non invasif, menggunakan cupping pada titik-titik meridian dan berfungsi memperbaiki mikrosirkulasi pembuluh darah (Ahmae, 2019). Sejalan dengan hasil penelitian oleh (Susi Susanah, Ani Sutriningsih, 2017) hasil uji statistik Wilcoxon terdapat selisih penurunan tekanan darah dengan selisih nilai mean pada sistole dan diastole dengan nilai $p$ value 0.000 yang berarti nilai $p<0,50$ artinya terdapat pengaruh terapi bekam terhadap penurunan tekanan darah pada penderita hipertensi di Poliklinik Trio Husada Malang.

(Anees et al., 2015) menjelaskan terapi kerja bekam menurut teori nitri oksida (NO) bahwa zat NO mempunyai peranan penting dalam trauma bekam seperti bekam pada kasus hipertensi, dimana zat NO bereperan dalam vasodilatasi pembuluh darah sehingga menyebabkan penurunan tekanan darah. Fungsi lain dari zat NO adalah anti trombotik, relaksasi otot dan juga anti inflamasi.

Majid, 2009 dalam(Risniati et al., 2019) bahwa di bawah kulit, otot, maupun tendon terdapat suatu titik/ point yang mempunyai sifat istimewa. Titik/ point tersebut saling berhubungan membujur dan melintang membentuk jaring-jaring (jala) yang diidientikkan dengan meridian tubuh. Jala ini berhubungan yang erat antar bagian tubuh, dan dapat bereaksi secara serentak. Kelainan yang terjadi pada satu point dapat menular dan memengaruhi poin lainnya.

Sejalan dengan penelitian oleh (Sormin, 2019) menyatakan Banyaknya jalur neuronal yang saling berinteraksi untuk mengatur aliran impuls saraf otonom memberi banyak peluang untuk integrasi berbagai stimulus yang mempengaruhi tekanan darah, seperti faktor emosi (takut, marah, cemas), stress fisik (nyeri, kerja fisik, perubahan suhu), kadar oksigen dalam darah, dan glukosa, juga level tekanan darah yang di kontrol oleh baroreseptor

Menurut asumsi peneliti pemberian terapi bekam dengan durasi seminggu sekali selama 7 menit memberikan perubahan pada tekanan darah klien. Hal ini disebabkan ketika pemberian terapi bekam kering, klien menerima dengan rileks disamping itu kontrol perilaku seperti adaptasi stress, aktivitas fisik, pola diet juga bisa mempengaruhi tekanan darah klien.

\section{Pengaruh Terapi Bekam Kering Terhadap Tekanan Darah Pada Pasien Hipertensi Primer}

Hasil analisis uji Uji Paired t test pada tekanan darah sistolik diperoleh nilai $p$ value sebesar 0,000 dan tekanan darah diastolik diperoleh nilai $p$ value sebesar 0,001 yang berarti ada pengaruh tekanan darah sistolik dan diastolik sebelum dan sesudah diberikan terapi bekam kering.

Sejalan dengan hasil penelitian oleh (Surahmat \& Damayanti, 2019) dengan judul penellitian Pengaruh Terapi Bekam Dalam Menurunkan Tekanan Darah Pada Pasien Hipertensi di Rumah Bekam Palembang menggunakan uji wilcoxon didapatkan nilai $\mathrm{p}$ value $0,000(<0,05)$ yang berarti ada pengaruh yang signifikan pemberian terapi bekam terhadap penurunan tekanan darah sebelum dan setelah intervensi. 
Bekam berperan menenangkan sistem saraf simpatik (simpatic nervous system). Pergolakan pada sistem saraf simpatik ini menstimulasi sekresi enzim yang berperan sebagai sistem angiotensin renin. Setelah sistem ini tenang dan aktivitasnya berkurang, tekanan darah akan turun (Ahmae, 2019). Adapun beberapa manfaat dari terapi bekam, yaitu mengeluarkan angina, toksin, dan kolesterol yang berbahaya dari tubuh, menghilangkan rasa sakit, memulihkan fungsi tubuh, melancarkan peredaran darah, menajamkan penglihatan, meningkatkan daya ingat dan kecerdasan, meningkatkan system imun (Zaki, 2012).

Prinsip kerja bekam adalah menyedot permukaan kulit pada titik stimulasi meridian. Penyedotan permukaan kulit menyebabkan bendungan local pada titik stimulasi meridian sehingga menyebabkan hipoksia dan radang. Proses ini dapat memperbaiki mikrosirkulasi dan fungsi sel dengan cepat. Stimulasi kekebalan tubuh terjadi karena peningkatan elastisitas spektrin dari 15 hari setelah terapi bekam kering, sehingga daya tahan tubuh meningkat baik sebagai pencegahan maupun perlawanan terhadap penyakit (Risniati, Y., Afrilia, A. R., Lestari, T. W., \& Siswoyo, H, 2019).

Asumsi peneliti ketika pembuluh darah sudah mengalami vasodilatasi maka hantaran hangat akibat penekanan yang tepat pada titik-titik meridian tubuh dapat menstimulasi saraf-saraf superfisial kulit untuk diteruskan ke hipotalamus lebih tepat. Sistem saraf desenden melepaskan apiat endogen seperti hormone endorphin di dalam tubuh dan meningkatkan pengeluaran hormone dopamin. Respon ini menyebabkan peningkatan aktivitas kerja system saraf parasimpatis yang berfungsi mengontrol aktivitas yang berlangsung dan bekerja saat tubuh rileks.

\section{SIMPULAN DAN SARAN}

Hasil uji statistic menggunakan uji Paired t test menunjukkan ada pengaruh terapi bekam kering terhadap tekanan darah pada pasien Hipertensi Primer dengan $\mathrm{p}$ value systole 0,000 dan $\mathrm{p}$ value diastole 0,001 . Terapi bekam kering dapat dijadikan sebagai terapi alternatif atau pendukung untuk perawatan klien dnegan Hipertensi. Studi ini menunjukkan hubungan yang jelas antara bekam kering dan tekanan darah pada pasien dengan hipertensi primer. Oleh karena itu, terapi bekam kering dapat digunakan sebagai tambahan untuk terapi konvensional, yang memungkinkan pengurangan pemberian dosis obat antihipertensi tertentu. Untuk hubungan penurunan tekanan darah oleh terapi bekam dan pengurangan rasa nyeri pelu diteliti lebih lanjut.

\section{DAFTAR PUSTAKA}

Ahmae, R. S. (2019). Bekamnya, Penyakit dan Terapi Dasar-Dasar Llmiah Terapi Bekam (XI). Thibbia.

Anees, S., Arafath, Y., \& Chisholm, K. (2015). Hijamah (Cupping therapy) as a 
Preventive Medicine-A Retro-Prospective Analytical Study. International $\begin{array}{llll}\text { Journal of } & \text {..., } & 4(2), & 88-100 .\end{array}$ http://prlpublisher.com/journal/index.php/ayush/article/view/67

Badan Penelitian dan Pengembangan Kesehatan RI. (2018). Laporan Nasional Riset Kesehatan Dasar. Kementrian Kesehatan RI, 1-582.

Dinas Kesehatan Kabupaten Gianyar. (2017). Profil Kesehatan Kabupaten Gianyar Tahun 2016. $1-187$. http://www.diskes.baliprov.go.id/files/subdomain/diskes/Juni 2017/Profil Kesehatan Gianyar 2016.pdf

Dinas Kesehatan Provinsi Bali. (2017). Profil Kesehatan Provinsi Bali Tahun 2015. $\begin{array}{llll}\text { Profil Kesehatan } & \text { Provinsi }\end{array}$ http://www.diskes.baliprov.go.id/files/subdomain/diskes/Profil Kesehatan Provinsi Bali/Tahun 2015/Bali_Profil_2015.pdf

Jansen, S., Karim, D., \& Misrawati. (2012). Efektivitas Terapi Bekam Terhadap Penurunan Tekanan Darah pada Penderita Hipertensi Primer.

Kemenkes.RI. (2014). Pusdatin Hipertensi. Infodatin, Hipertensi, 1-7. https://doi.org/10.1177/109019817400200403

Kemenkes RI. (2014). Situasi kesehatan jantung. Pusat Data Dan Informasi Kementerian Kesehatan $R I$, 3. https://doi.org/10.1017/CBO9781107415324.004

Muhadi. (2016). JNC 8 : Evidence-based Guideline Penanganan Pasien Hipertensi Dewasa. Cermin Dunia Kedokteran, 43(1), 54-59.

PERHI. (2019). Konsensus Penatalaksanaan Hipertensi 2019. Indonesian Society Hipertensi Indonesia, 34-35.

Risniati, Y., Afrilia, A. R., Lestari, T. W., \& Siswoyo, H. (2019). Pelayanan Kesehatan Tradisional Bekam : Kajian Mekanisme, Keamanan dan Manfaat Traditional Cupping Therapy : A Review of Mechanism, Safety and Benefits. Jurnal Penelitian Dan Pengembangan Pelayanan Kesehatan, 3(3), 212-225.

Sormin, T. (2019). Pengaruh Terapi Bekam Terhadap Tekanan Darah Penderita Hipertensi. Jurnal Ilmiah Keperawatan Sai Betik, 14(2), 123. https://doi.org/10.26630/jkep.v14i2.1294

Surahmat, R., \& Damayanti, N. R. (2019). Pengaruh Terapi Bekam Dalam Menurunkan Tekanan Darah Pada Pasien Hipertensi Di Rumah Bekam Palembang. Majalah Kedokteran Sriwijaya, 49(1), 43-49. https://doi.org/10.32539/mks.v49i1.8323

Susi Susanah, Ani Sutriningsih, W. (2017). Influence of Cupping Therapy Against Blood Pressure Drop on Hypertension Patients At Polyclinic Trio Husada Malang. Journal Nursing News, 2(1), 281-291.

Zaenurrohmah, D. H., \& Rachmayanti, R. D. (2017). Relationship Between 
Bali Medika Jurnal.

Vol 8 No 1, 2021: 90-98

ISSN : 2615-7047

DOI: https://doi.org/10.36376/bmj.v8i1

Knowledge and Hypertension History with Blood Pressure Control in Elderly.

Jurnal Berkala $\quad$ Epidemiologi,
https://doi.org/10.20473/jbe.v5i22017.174-184

$5(2)$

174.

Zaki, M. (2012). Lima Terapi Sehat. T Elex Media Komputindo. 